\title{
Single coronary ostium, unilateral pulmonary atresia and MAPCA with tetralogy of fallot in a young adult: a rare association
}

\author{
Vora $\mathbf{K}^{1}$ \\ ${ }^{1}$ Dr. Keyur Vora, Department of Cardiology, Care Hospitals, The Institute of Medical Sciences, Surat, Gujarat, India \\ Address for correspondence: Dr Keyur Vora, Email: drkeyurvora@gmail.com
}

\begin{abstract}
Tetralogy of Fallot (TOF) is the most common form of cyanotic congenital heart disease (CHD). The mortality rate in untreated patients reaches $50 \%$ by age 6 years. It is also the most common form of cyanotic CHD with survival upto adulthood. However, TOF with both coronary and pulmonary vasculature anomalies is an extreme variant. We report a case of TOF with single coronary ostium (SCA); atretic branch pulmonary arteries and major aortopulmonary collateral artery (MAPCA) with relatively symptomless period upto 22 years of age.
\end{abstract}

Key words: Tetralogy of Fallot, congenital heart disease, single coronary ostium

\section{Introduction}

TOF is a cyanotic congenital cardiac malformation that consists of an interventricular communication, also known as a ventricular septal defect, obstruction of the right ventricular outflow tract, override of the ventricular septum by the aortic root, and right ventricular hypertrophy. This combination of lesions occurs in 3 of every 10,000 live births, and accounts for $7-10 \%$ of all congenital cardiac malformations [1].
Among patients of TOF, pulmonary atresia occurs only in $12 \%$ of cases [2]. Pulmonary atresia with VSD is considered the extreme end of the anatomic spectrum of TOF. In cases of hypoplastic pulmonary artery, pulmonary blood supply is from MAPCAs [3]. Moreover, the incidence rate of anomalous distribution of coronary arteries in TOF is $5-14 \%$ [4]. Our case report depicts the classic combination of abnormal vascular relationship in TOF, contributing to enhanced saturation and survival benefits.

\section{Case Description}

A 22-year female patient presented with complains of intermittent self limiting palpitation and difficulty in breathing upon exertion since last 5 years; aggravating since last 6 months. Patient had NYHA Class III dyspnea and Grade III clubbing. Patient had peripheral capillary oxygen saturation $(\mathrm{SpO} 2)$ of $75-80 \%$ at rest. On auscultation, patient had grade 3/6 pansystolic murmur prominent over mitral and tricuspid areas. Chest roentgenograms revealed a mild cardiomegaly and decreased pulmonary vascularity on left side. The electrocardiogram demonstrated sinus rhythm and evidence of right ventricular hypertrophy.

Two dimensional echocardiography study reveals 50\% overriding of aorta with 13-13.5 mm of perimembranous ventricular septal defect having left to right shunt (Fig.1A). Evidence of right ventricular apical hypertrophy, mild tricuspid regurgitation and mild pulmonary hypertension was noted with peak right ventricular systolic pressure of 36 $\mathrm{mmHg}$ by TR jet method. Moreover, mild right ventricular dysfunction was evident by TAPSE (Tricuspid Annular Plane

Manuscript received: $06^{\text {th }}$ December 2016

Reviewed: $12^{\text {th }}$ December 2016

Author Corrected: 20 $0^{\text {th }}$ December 2016

Accepted for Publication: $31^{\text {st }}$ December 2016 
Systolic Excursion) method. No significant valvular or subvalvular gradient noted in main pulmonary artery. Pulmonary artery flow was appreciated with limited RPA flow. Interestingly, no evidence of flow or gradient found at left pulmonary artery level. It was imperative to correlate left lung ventilation-perfusion in the absence of visible LPA flow. This prompted to perform cardiac catheterization study to determine the pulmonary circulation anatomy and possible alternative way of left lung perfusion. The catheterization study was challenging in terms of very interesting and critical analysis of anomalous cardiopulmonary vasculature.

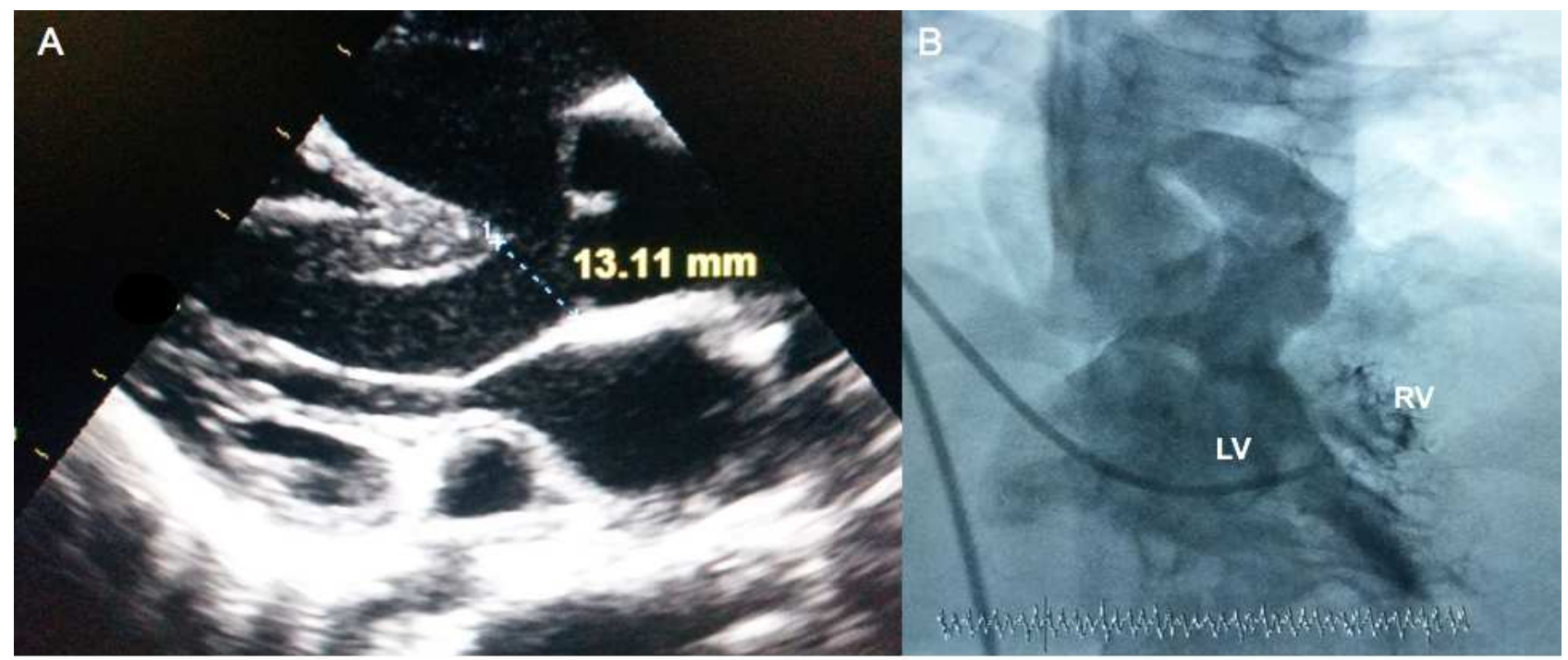

Figure-1: A) Parasternal long axis view shows 50\% overriding of aorta with approximately 13.12 mm perimembranous ventricular septal defect (VSD) on echocardiography. B) Left ventriculogram with contrast filling of right ventricle through VSD.

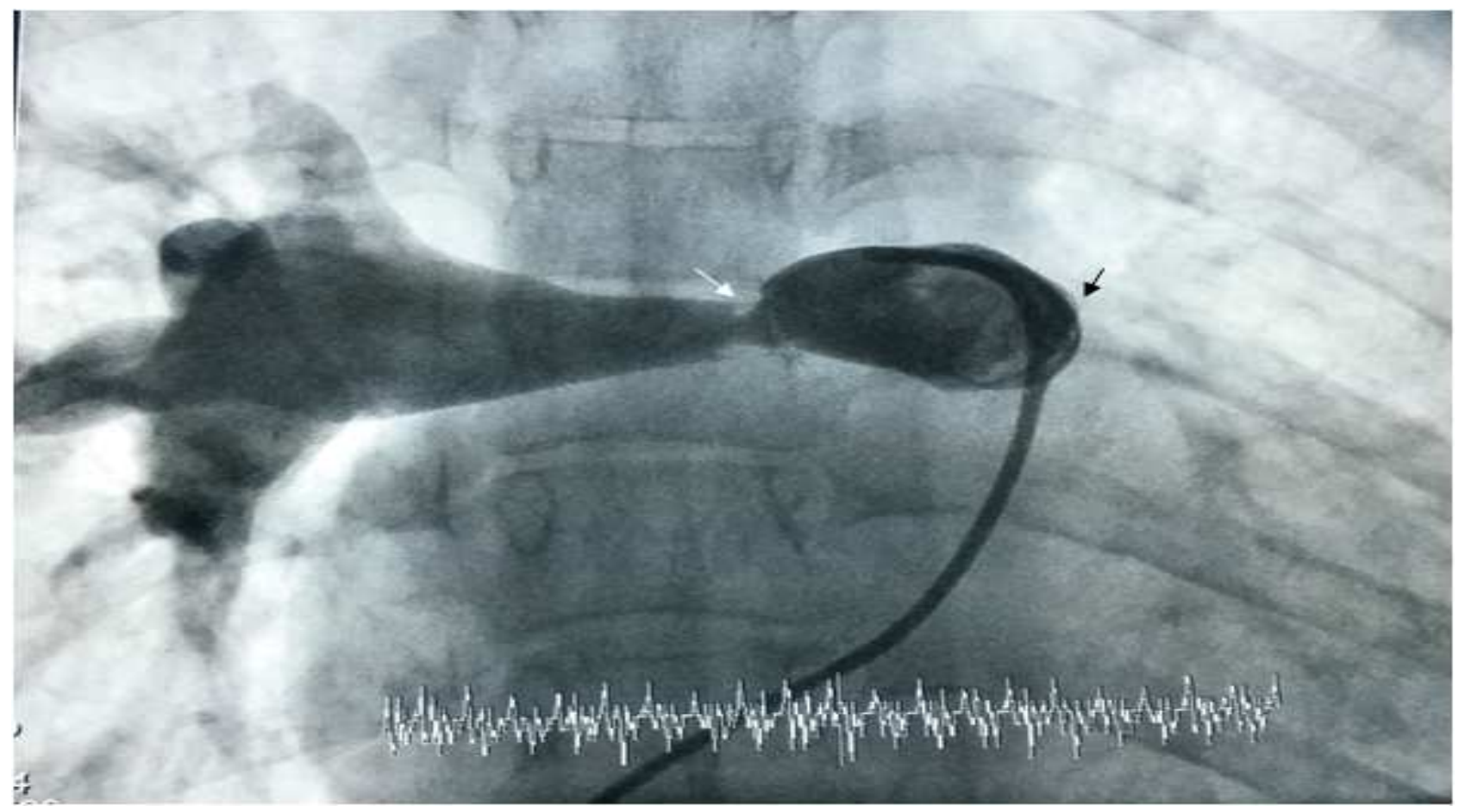

Figure-2: Contrast pulmonary angiography reveals significant narrowing and stenosis in right pulmonary artery (white arrow) and absence of flow in left branch of pulmonary trunk suggestive of unilateral left sided pulmonary atresia (Black arrows). 


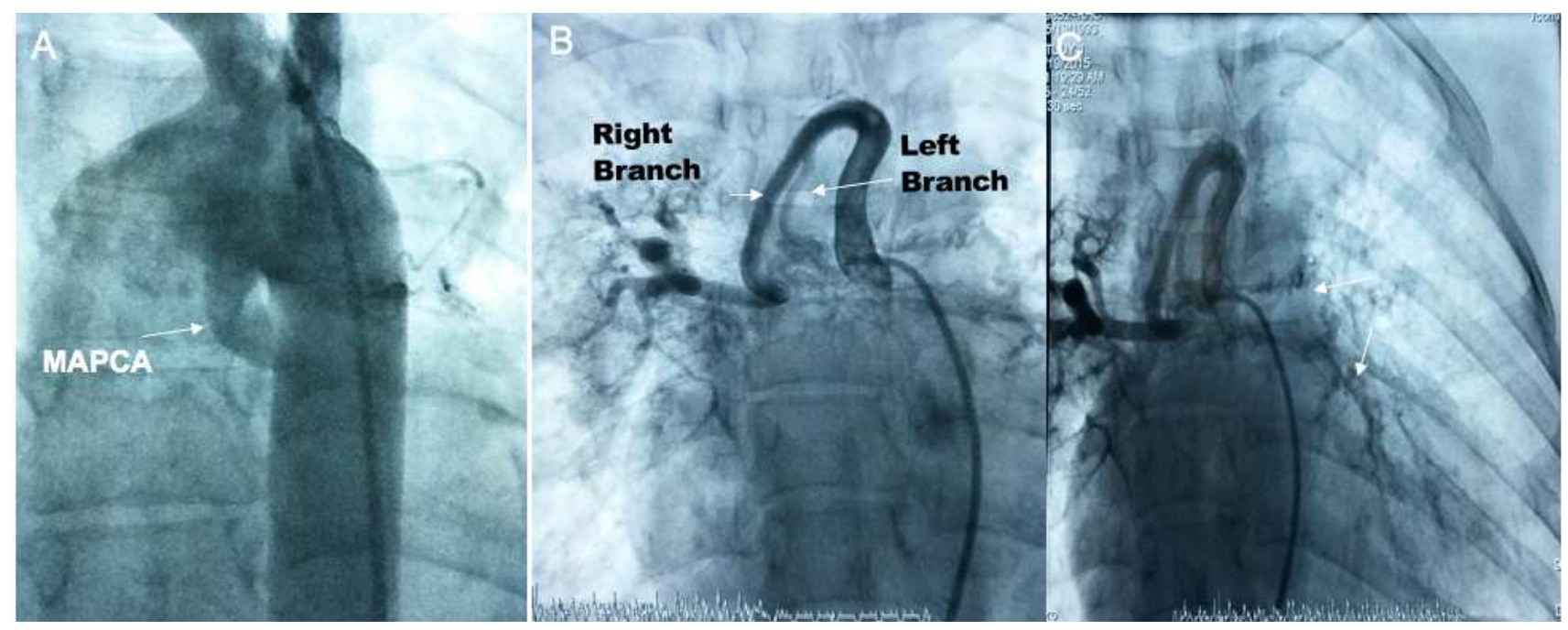

Figure-3: A) Aortogram reveals presence of MAPCA arising from arch of aorta and proceeds with curved path towards right lung before bifurcating into right and left branches. B) Right branch further divides into lobar branches and partially supplies a small area of upper and middle lobes of right lung. C) Left branch is not perfused well and supplies a substantial perihilar area of left lung.
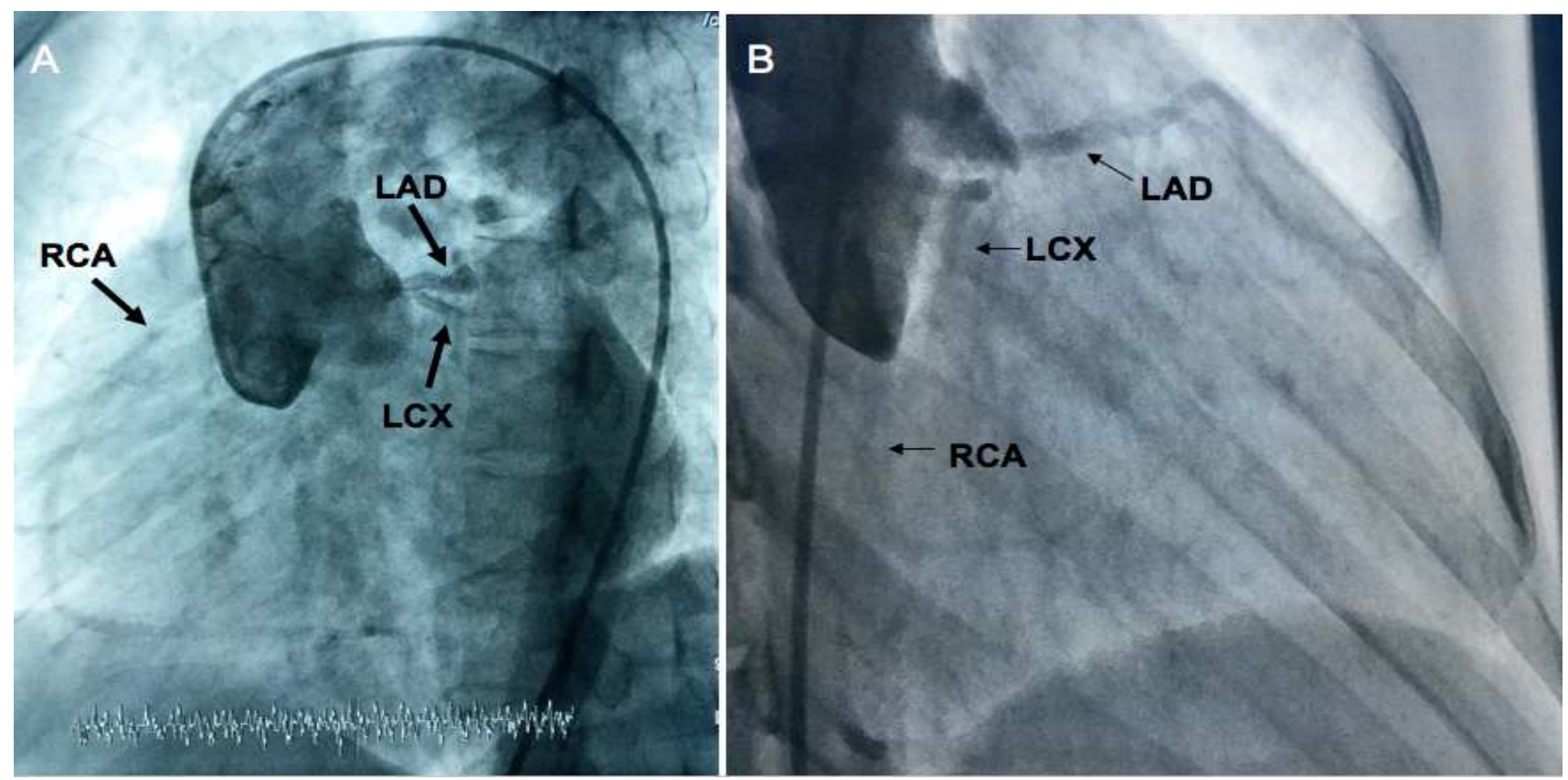

Figure-4 (A \& B): Coronary angiogram shows simultaneous filling of RCA, LCX and LAD coronary arteries suggestive of single coronary ostium.

The main pulmonary trunk and pulmonary valve were non-atretic. However, right pulmonary artery had critical stenosis after $7 \mathrm{~mm}$ of length post-bifurcation (Fig.2; white arrow). Presumably, left pulmonary artery was atretic with no flow which correlated with echocardiography findings (Fig.2; black arrow). Moreover, arch aortogram reveals presence of major aortopulmonary collateral artery (MAPCA) arising from underside of arch of aorta and continues towards right lung with a curved path (Fig.3A). Major MAPCA bifurcates into right and left branches (Fig.3B; white arrows). Right branch further divides into lobar branches and partially supplies small area of upper and middle lobes of right lung (Fig.3C; white arrows). Left branch is poorly fed from major MAPCA and divides into multiple short small-sized branches and supplies a substantial portion of perihilar area of left lung (Fig.3C; white arrows). 
On the rare side, simultaneous contrast filling of left anterior descending (LAD) artery, left circumflex (LCX) artery and right coronary (RCA) arteries reveals all coronary arteries originating from single side of aorta; suggestive of single coronary ostium (Fig.4A,4B; black arrows). Additionally, left ventriculogram was performed to confirm the left to right shunt through perimembranous ventricular septal defect (Fig.1B).

Patient is on conservative treatment as required for symptomatology. She had marked improvement with treatment. She was further advised to have regular follow up and to maintain medical records. Among rare instances, TOF patients have been reported to reach more than 40 years of age.

\section{Discussion}

Our case is unique in terms of survival and relatively symptomless period upto adult age. Considerable progress has been made in the repair strategy for TOF, based on improved understanding of post repair physiology. However, associations of rare coronary and pulmonary vasculature anomalies in TOF patients are unique challenges that need extraordinary measures on case by case basis. There are important implications for timing as well as technique of surgery. Based on limited data, excess mortality for age group 20-39 years was higher compared with those in a younger age group during the first 10 years after surgery [5]. Most reports emphasized determining ductal dependency in the neonatal period, with the need for palliative BlalockTaussig shunt surgery in the immediate neonatal period versus surgical repair done electively at a later age [6,7]. Patients with large MAPCAs and unrestricted pulmonary blood flow are more prone to develop pulmonary arterial hypertension (PAH) and congestive cardiac failure (CCF). Survival of patients with TOF and pulmonary atresia depends upon adequacy of pulmonary blood flow [8].

In our patient, blood flow was adequate in both lung fields with uneven vascular distribution. Our patient had TOF with pulmonary atresia and pulmonary circulation was through MAPCAs only. So, there was less chance of developing pulmonary arterial hypertension and congestive cardiac failure. Considering the body mass index (BMI) and physiological adaptations, survival is relatively asymptomatic upto certain age only. Survival in such cases has not been widely studied in literature. This case report indicates that variants of TOF are likely to survive more due to compensated saturation by variant vascular relations as well as delayed morbidity and mortality upto adult age.

\section{Conclusion}

Our case report indicates the importance of systematic evaluation of vascular anomalies associated with TOF.
The variants of TOF are underdiagnosed and may implicate poor outcome of routine surgical approach. Routine coronary angiogram and pulmonary angiogram play an unparalleled role to diagnose variants of TOF as depicted in our case report. Advanced imaging methodologies promise more precise diagnosis among variants of cyanotic congenital heart diseases. Continued evolution is anticipated in terms of diagnosis, treatment and prognosis among variants of TOF.

Funding: Nil, Conflict of interest: None initiated, Permission from IRB: Yes

\section{References}

1. Bailliard F, Anderson RH. Tetrology of Fallot. Orphanet J Rare Dis. 2009 Jan 13;4:2. doi: 10.1186/1750-1172-4-2.

2. Garne E, Nielsen G, Hansen OK, Emmertsen K. Tetralogy of Fallot. A population-based study of epidemiology, associated malformations and survival in western Denmark 1984-1992. Scand Cardiovasc J. 1999;33(1):45-8.

3. Asija R, Hanley FL, Roth SJ. Postoerative respiratory failure in children with tetralogy of fallot, pulmonary atresia, and major aortopulmonary collaterals: a pilot study. Pediatr Crit Care Med. 2013;14:384.

4. Jureidini SB, Scott Appleton RR, Nouri S, Crawford CJ. Detection of coronary artery abnormalities in tetralogy of fallot by two-dimensional echocardiography. J Am Coll Cardiol. 1989;14(4):960967. doi:10.1016/0735-1097(89)90473-

5. Pokorski RJ. Long-term survival after repair of tetralogy of Fallot. J Insur Med. 2000;32(2):89-92.

6. Hornberger LK, Sanders SP, Sahn DJ, Rice MJ, Spevak PJ, Benacerraf BR, McDonald RW, Colan SD. In utero pulmonary artery and aortic growth and potential for progression of pulmonary outflow tract 
obstruction in tetralogy of Fallot. J Am Coll Cardiol. 1995 Mar 1;25(3):739-45.

7. Pepas LP, Savis A, Jones A, Sharland GK, Tulloh RM, Simpson JM. An echocardiographic study of tetralogy of Fallot in the fetus and infant. Cardiol Young. 2003 Jun;13(3):240-7.
8. Bertranou EG, Blackstone EH, Hazelrig JB, Turner ME, Kirklin JW. Life expectancy without surgery in tetralogy of Fallot. Am J Cardiol. 1978 Sep;42(3):45866.

\section{How to cite this article?}

Vora K. Single coronary ostium, unilateral pulmonary atresia and MAPCA with tetralogy of fallot in a young adult: a rare association. Int J Med Res Rev 2016;4(12):2226-2230.doi:10.17511/ijmrr. 2016.i12.25. 